method should be given a thorough trial in those cases where no tear can be seen. It means a great deal of patience on the part of patient and medical man, but the satisfactory result more than compensates for this.

5. It has been my experience in more than one case of inflammation of the optic nerve that where the cause of the trouble cannot be definitely traced and the condition does not respond to treatment, sufficient " blood-letting" from a high operation in the nose often tends to bring about favourable results.

\title{
ROBERT BRUDENELL CARTER
}

BY

R. R. JAMES

WOODBRIDGE

BRUDENELL CARTER occupied a position intermediate between the giant founders of modern ophthalmology, such as Bowman and the elder Critchett, and the more modern consolidators of our science, such as Nettleship and William Lang. He was born in the same year as Sir Jonathan Hutchinson. Bowman and Critchett were roughly 12 and 11 years his senior, while Nettleship was about 17 years his junior.

Carter was born on October 2, 1828. He came of a very old family, one branch of which was long settled at St. Columb Major, in Cornwall. ${ }^{1}$ His own researches into his family history traced his descent from an Esquire of Higham, Beds. in the time of Edward the Fourth. ${ }^{2}$ Among his ancestors were some distinguished men and women. His great aunt was Elizabeth Carter, the poetess and translator of Epictetus whose "I canna be fashed" evoked the scorn of Miss Matty Jenkyns, in Cranford. His grandfather was the Rev. Henry Carter, Rector of Little Wittenham, Berks. for more than half a century, and his paternal grandmother was descended from John Wallis, F.R.S., the astronomẹr and mathematician. Carter's father was a Major in the Royal Marines. His mother died in giving birth to R. B. Carter and in consequence the father took little interest in the baby, who owed his christian names to the kindness of a friend of Major Carter, the then Earl of Cardigan.

Carter was educated at private schools and began his professional education as an apprentice to a general practitioner. He subsequently entered the London Hospital as a student and qualified M.R.C.S. in 1851. In the following year he took the L.S.A., these two diplomas constituting at that time the usual double qualification. 


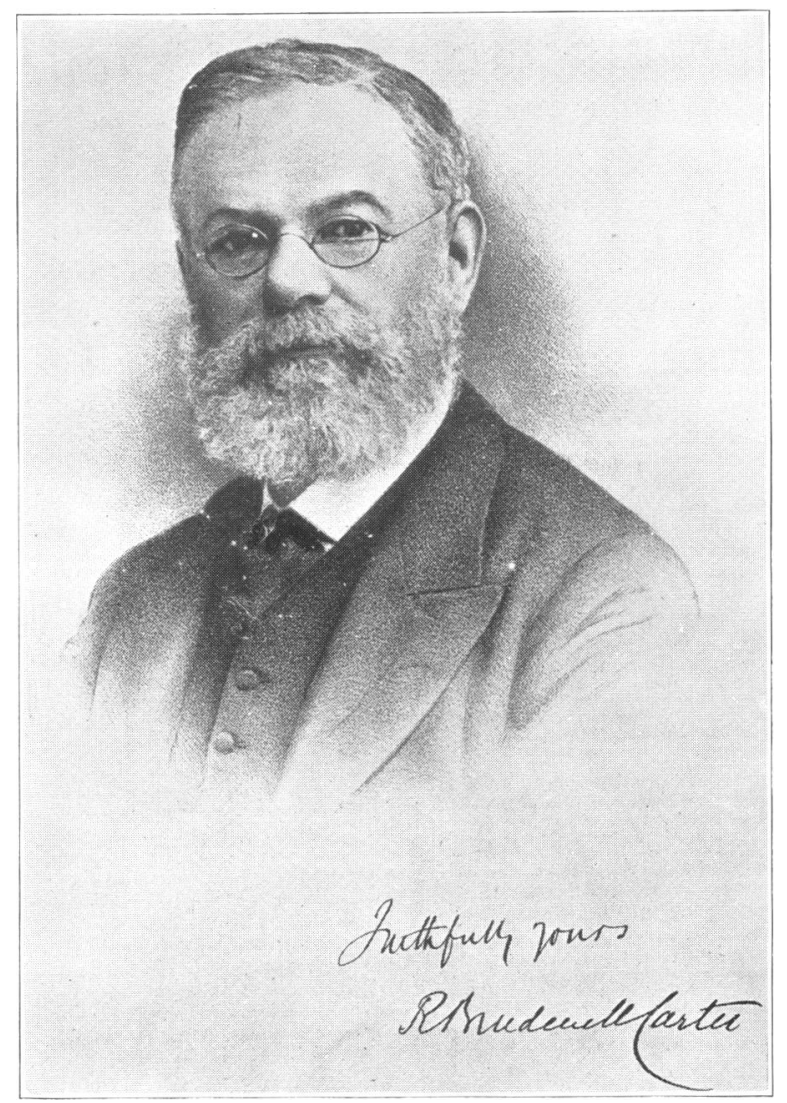

Block kindly lent by the American Medical Association.

R. BRUDENELL CARTER, 1828-1918. 
In a letter to the Editor of the Lancet, which was epitomised in that Journal's obituary notice of Carter, he wrote :-

"As I could not afford the six years hospital practice as a student necessary for the F.R.C.S., I determined from the first to maintain my knowledge of anatomy and to keep fully abreast of surgery. The result was that as soon as I had completed the necessary 12 years as a member, I was able to go up from my country practice for the Fellowship examination without either rest for study or coaching, and to pass."

As a matter of fact Carter was in general practice until he was 40 years of age. He was for ever on the move. He started in Leytonstone and while there published his first book, "on the Pathology and Treatment of Hysteria" (1853). Soon after this he moved to Putney, whence. was issued his work on "The influence of Education and Training in preventing Diseases of the Nervous System" (1855).

About this time he went out to the Crimea as a Staff Surgeon in the Army. On his return he settled in Nottingham and took an active part in the establishment of the Eye Hospital there. In 1862 he moved to Stroud, Gloucs., and was again prominent in the foundation of the Gloucester Eye Hospital. He became F.R.C.S. in 1864 and in 1868 he moved to London. $\mathrm{He}$ was elected a member of the Staff of the Royal South London Hospital (now the Royal Eye Hospital) in 1869 and in the following year was appointed Lecturer in ophthalmic surgery at St. George's Hospital Medical School and Ophthalmic Surgeon to the Hospital.

While serving in the Crimea, Carter became acquainted with W. H. Russell, the celebrated war correspondent of the Times, and on the advice of the latter he sent in a series of letters from the front which were published in the Times. These were so highly thought of that when, 14 years later, Carter decided to come to London, he applied to the Times for a post on the Staff, to which he was shortly after elected. He wrote leaders for the Times for 50 years and wrote in a similar capacity for the Lancet for most of the same long period.

He held the Crimean medal and was a Knight of Justice of the Order of St. John of Jerusalem.

Carter's place in ophthalmology falls naturally into two compart. ments, firstly the surgeon and secondly the author.

As a surgeon he was probably one of the most accomplished men of his day. When the writer first joined the eye department at St. George's Hospital, now more than 30 years ago, a few of Carter's old patients were still attending with some regularity. He remembers a female whose face was heavily scarred as a result of lupus; her corneae were a mass of nebulae. Carter had performed an optical iridectomy on each eye with very good results, the patient 
having something like $6 / 60$ in each eye for distance with a myopic spherical glass, and useful near vision.

Carter's iris scissors are perhaps not well known to the younger members of the profession. They are a beautiful little instrument with very short blades and springy handles which interlock. This instrument was designed to be passed into the anterior chamber with closed blades through a corneal section, the blades being laid flat against the iris. When opened a small fold of iris protruded between them and was cut off with a single snip, leaving a small more or less circular hole to act as a new pupil.

Carter had sole charge of the eye department at St. George's until Adams Frost was elected Assistant Ophthalmic Surgeon in 1881 , and he continued a member of the Staff for another eleven years. He was also for some years Ophthalmic Surgeon to the National Hospital, Queen Square, and on retirement was made Consulting Ophthalmic Surgeon to both Institutions.

In 1875 Carter brought out his "Practical Treatise on Diseases of the Eye." This is a book that well repays perusal even to-day. It consisted practically of the course of lectures which he delivered to the students of St. George's Hospital. In the history of the Hospital issued to commemorate its bi-centenary, Blomfield speaks of Carter's lectures as follows:- "Listening to Carter's lectures was like listening to a series of leading articles on the diseases of the eye. They were so perfectly composed and smoothly delivered that they might have been reproduced verbatim." From the same source we learn that Carter used to perform the eye operations at St. George's, dressed always in a frock coat and with a ring on one of his hands, which were unusually white.

The Practical Treatise forms an octavo volume of 581 pages. There are four lithograph plates which were executed from drawings by Carter's eldest son, but the number of illustrations in the text is only 91 , and these are for the most part either reproductions of instruments, or simple diagrams such as would be sketched on a blackboard.

Ophthalmic pathology 60 years ago was in its infancy and Carter was above all else a clinician, and so we find no pathological illustrations. The lay-out of the book is quite in the modern style. $\mathrm{He}$ deals with the diseases of the eye on an anatomical basis and furnishes chapters on the use and selection of spectacles, on the principles of ophthalmic surgery and therapeutics, on the ophthalmoscope and the examination of the eye.

A few extracts from some of his chapters may be of interest. His chapter on the ophthalmoscope begins as follows:- "For many years it was considered impossible to see into the interior of the eye ; and the assumed impossibility long rested on the strange hypothesis that the pigment of the choroid absorbed all the light 
which entered and suffered none to return. This hypothesis was disproved by the late Mr. Cumming, who, in 1846, when a student at the London Hospital, showed that, in certain positions of the observer and the person observed, a luminous reflex could be obtained from the eye. Mr. Cumming's premature death prevented him from pursuing his investigations; but, about 1848, the late $\mathrm{Mr}$. Charles Babbage took up the subject as a purely optical problem and constructed an ophthalmoscope which left little to be desired. He placed it in the hands of an English ophthalmic surgeon, who unfortunately alike for his own reputation and for the scientific credit of his country, did not perceive the practical value of the means of research thus given to him."

The English ophthalmic surgeon referred to in this paragraph was, of course, Wharton Jones.

In his chapter on the principles of ophthalmic surgery, Carter allows the sarcastic bent of his mind full play.

Referring to Beer's statement that an ophthalmic surgeon must spoil a hatful of eyes before he cures one, he says:- "if we regard Beer's saying as even a gross exaggeration, repeated chiefly for its vivacity and force, we cannot thus explain away the familiar maxim of political economy that all learners spoil a portion of raw material."

He insists on the need for adequate training of the hands, and refers to "a contrivance, with a name in shopkeepers' Greek, which enables musicians to acquire strength and flexibility of finger without the production of sounds distressing to those in their vicinity," and states his opinion that the vast majority of persons can train their hands to do ophthalmic operations. But " those cannot become ambidextrous who have been born ambisinistrous."

" The Hebrews, again, obviously as a result of the traditions by which their national life has been controlled, are conspicuously inferior to Gentile races in mechanical dexterity; and I have been told of a Jewish ophthalmologist, the subtlety of whose brain work is unsurpassed, that he "operates from the shoulder.'"

"Many surgeons of great and deserved repute have invented each a single instrument, such as Beer's knife or Tyrrell's hook; and some have invented more than one . . . But, as a rule the invention of many instruments by a surgeon may be accepted as a sufficient proof of his clumsiness; and when, without valid reason, any single operator has his peculiar scissors, his peculiar hook, and his peculiar forceps, and his peculiar scoop, all called by his name, it is more than probable that the gift of fingers has not been bestowed upon him. The safest man is he who never invented an instrument in his life, but whose daily practice affords evidence that he can use those which have been invented for him by others." Fig. 46 in his book shows a left hand holding a pair of scissors. 
In discussing contagious ophthalmia, Carter says that its worst effects are seen most commonly in pauper schools. Inmates of such schools are "children who have nearly all been insufficiently, or at best irregularly fed, while under parental control. And many of them, as orphans, are the presumptive inheritors of some form of constitutional disease." He notes that many, before admission to such schools, have enjoyed the liberty of street Arabs, and have been accustomed to the open air of the streets, which, "if not of the best, would at least be many degrees more wholesome than that of a crowded schoolroom." When brought into school, "it does not always happen that they receive a proper diet; because the scale on which they are fed is liable to be determined by the authorities who are unacquainted with the dietetic requirements of growing children, and who do not seek advice from those who are capable of instructing them." He next refers to the Lancet Report on the epidemic of ophthalmia at Anerley in 1872; gives details of the dietary which appears to have been of a monotonous nature. This diet, he says, "will not sustain health." He next deals with the sleeping accommodation and condemns it roundly, while he has some illuminating remarks on the clothing of the boys, which is commonly made of "fustian or corduroy." At Anerley the washing accommodation was insufficient, and " at one time a few jack-towels were common to a large number of children." "I have obtained from a private source a copy of a report made to a Government Inspector by a late Medical Officer of the Hanwell Schools. Of 1,062 children there, only 182 had escaped ophthalmia . . . In another part of the report I find it stated that out of 1,195 children 347 had 'granular lids after ophthalmia,' and I have no doubt that in all or in nearly all of these the sight would eventually be greatly impaired, and that in many cases it would be wholly lost." ... "The Local Government Board has therefore been premature in felicitating itself, in a recently published report, on the fact that out of a very large number of children who were affected at Anerley, in no one instance has the sight been anything like lost." And he ends his description of ophthalmia neonatorum as follows:- "I cannot too strongly express my conviction that no infant should ever lose its sight from this affection; and that sight cannot be so lost under the observation of a competent medical man, except as a consequence of neglect or want of knowledge of a very flagrant character."

In speaking of sloughing corneal ulcer he emphasizes the value of an iridectomy in such cases and tells the following story :-

"Some years ago, when I was residing at Stroud, I had a crucial instance of the value of iridectomy in such a condition. A poor old man, whose name and face were alike unknown to me, came from one of the neighbouring villages with precisely the history given 
above. I placed him on a couch in my consulting room, and performed an iridectomy without assistance, and hence without an anaesthetic. He was so much shaken by the operation that I told him to sit down in an adjoining room, in order that he might recover himself before receiving final directions. I was called away for a short time to another case, and when I returned the patient was gone. He had not understood that I had anything more to say to him, and went away as soon as he had rested and felt better. I did not know where he came from, and could not identify him for some weeks afterwards, when I found his eye had recovered so quickly that he had not thought it worth while to pay me a second visit. The ulcer was firmly healed . . . and the gap left by the iridectomy afforded useful vision."

To us of the present day it will seem queer that Carter, in speaking of persistent pupillary membrane, comments on its rarity, "insomuch that I have only seen two examples of it."

In the chapter on the use and selection of spectacles he refers to his famous case which was recorded in the Transactions of the Clinical Society, 1874-5. A young man, reading for honours at Oxford, had been attacked by symptoms which the local doctor attributed to some brain affection, and he was therefore advised to give up work and leave the University. This advice was shortly afterwards confirmed by a London consultant, who prescribed complete rest and a voyage to Australia. The boy actually went to Australia and returned no better. Carter was then consulted and found myopia $1 / 8$ in each eye, and that glasses had never been worn. He ordered glasses and cured the patient.

This case is classical for after the publication of Carter's paper men began to pay attention to eye strain and the need for refraction.

In 1877 Carter gave a course of Hunterian lectures at the Royal College of Surgeons. They were entitled "Defects of vision which are remediable by optical appliances." These lectures were referred to, I believe in the British Medical Journal, as "Carter's defects ;" whereupon the old gentleman retorted with some rather acid remarks about Ernest Hart's weakly. Carter also wrote "EyeSight-Good and Bad," 1881, and, being much interested in education, he wrote a famous paper on the artificial production of stupidity in schools. To my regret I have not been able to read this paper.

He delivered the Lettsomian Lectures at the Medical Society, of which he was later President; these lectures were concerned with the present day methods of dealing with cataract and were published in book form. Among his other publications were translations of $Z$ ander, on the ophthalmoscope and Scheffler, on ocular defects. With Adams Frost he was the author of a very good students' manual on "Diseases of the Eye," 1887. But, as if not satisfied with this 
large literary output he contributed chapters to Quain's Dictionary of Medicine and Holmes and Hulke's System of Surgery.

His work as 'leader writer' to the Times and the Lancet has already been noticed; he also wrote many letters to the Times, usually over the signature F.R.C.S.

His last book, entitled " Doctors and Their Work," appeared in 1903. It deals with many aspects of professional interest. He stresses the value of a knowledge of the English language, including grammar and composition, in both the preliminary and professional education of a medical student. He gives some amusing examples of malapropisms and tilts, in his best vein, against such words as "amphiblestroiditis" as a variant for retinitis. As he says, the originator of this word seems to have considered it as more sonorous than rete and to have overlooked the fact that $\dot{a} \mu \phi i B h_{\eta \sigma \tau} \rho \rho_{0}$ means specifically a casting-net. Another example of pseudo-classic taste is referred to as follows :- "I once knew a country cabinet maker, who constructed wooden frames covered with needlework for the purpose of surrounding polished fenders and protecting them from feet: He consulted the local schoolmaster as to the name by which the contrivance should be known; the latter suggested " antitribospodothecidion" which appears to mean an "against friction of the ashes receptacle."

Carter has a good word to say for the old practice of apprenticeship. He deals with such subjects as medical designations, the aims of medicine, the wishes of the patient, medical grievances, 'anti's' and quacks, professional eminence, specialism, speech and silence, etiquette, the insane, and medical women, and all his remarks are characterised by sound sense. A precis of his views on quacks is worth reprinting. "The amount of impunity enjoyed by quacks, and the extent of the prevalence of quackery, in any country must largely depend upon the provisions of the law;. and, in considering these provisions as they exist in England, where they are at least likely to be in general harmony with public opinion, it is impossible not to be struck by the contrast they present to any which have reference to the discharge of clerical or legal functions. In medicine and surgery the quack not only has a free hand, but he is practically assisted and encouraged by the State.

In relation to the Church and the Law he is in every case forbidden to take effective action; and in many cases any attempt to do so would bring him under the operation of penal enactments.

When the Medical Act of 1858 was introduced into the House of Commons, its principal sponsor, the Rt. Hon. W. Cowper, felt it necessary expressly to disclaim any endeavour to hinder or prevent illegal practice. He said that the projected Register would enable the public (if they were so disposed) to distinguish (not qualified 
men from quacks), but qualified from unqualified practitioners, and that it was proposed that public appointments should generally speaking, be held only by the former; but that he "was disposed jealously to guard the right of private individuals to consult whomsoever they please, whether they happened to be learned or unlearned.' In saying this he was no doubt appealing to the public opinion of the House, and he knew very well that any endeavour to prohibit unqualified practice would be unsuccessful. . . At the very time when this was occurring, and for many years previously, the practice of unqualified persons as solicitors was and had been strictly forbidden, with the complete approval both of public opinion and the Legislature. In other words the public were fully aware that the acts of sham lawyers, if permitted, would be attended with danger to the security of property; but they were not aware, or did not realise in any effective manner, that the acts of sham doctors would be attended with danger to the security of life. They did not want the sham lawyers : they did want the sham doctors.

The difference between the two cases is clearly brought out in two proverbs of approximately equal currency. One of them is that ' every man is either a fool or his own physician at forty '; the other is that "every man who is his own lawyer has a fool for his client." ",

From 1887 to 1900 Carter was a member of the General Medical Council.

I did not know Carter personally, but I often saw him at Hospital dinners in my early days. He was a popular man and a capital speaker. In an obituary notice in the St. George's Hospital Gazette, his old colleague, Adams Frost, wrote as follows :-

"As a clinical teacher I should hardly say that he was very successful. He was apt to take for granted a preliminary knowledge in his audience, which, notwithstanding an assumed appearance of wisdom, they seldom possessed. As an operater he was probably unsurpassed and his results both in hospital and private practice were excellent ... He was a fluent speaker on public occasions or in lighter after-dinner speeches. He had a great memory for anecdotes which he told with much gusto. His self-control was remarkable; even when addressing an unsympathetic or hostile audience. I never saw him lose his temper under the most extreme provocation inflicted by an incompetent assistant, but the hidden fire would reveal itself by a caustic remark, which would be more appreciated by the rest of his hearers than by the individual to whom it was ostensibly addressed. He did not suffer fools gladly and his sarcastic remarks made him some enemies, and led to a false estimate of his character. To those who knew him well he was a genial companion, and as the writer can testify, a most sympathetic and helpful friend. He was always a vehement opponent of the system of homoeopathy, and the lengthy and 
somewhat acrimonious correspondence between him and the late Lord Grimthorpe on this subject will be remembered. He ably exposed the hollowness of the theory and the futility of practice, and wrote with scorn of the dishonesty of those who practise orthodox

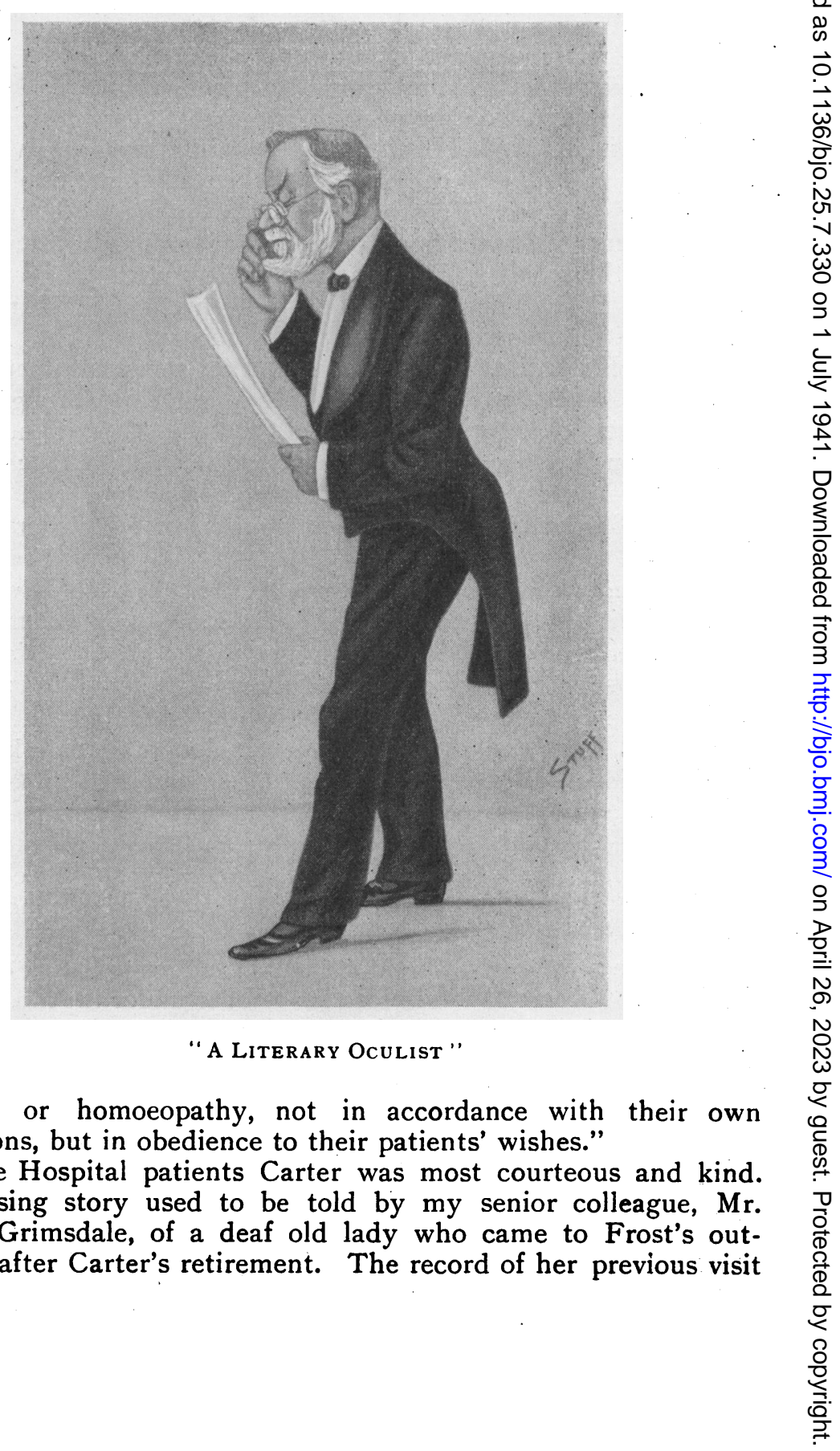

methods or homoeopathy, not in accordance with their own convictions, but in obedience to their patients' wishes."

To the Hospital patients Carter was most courteous and kind. An amusing story used to be told by my senior colleague, Mr. Harold Grimsdale, of a deaf old lady who came to Frost's outpatients after Carter's retirement. The record of her previous visit 
could not be found, and Frost, in his rather brusque manner, as was his custom, said 'Did you see me, Mam, at your last visit ?' The old lady replied, ' Oh, no sir, I saw a nice kind old gentleman.'

Carter was twice married and had several children. He died, in his 91 st year, on October 23, 1918, and was buried at the West Norwood Cemetery.

In the preparation of this paper I have consulted most of the works mentioned as well as the obituary notices published in the Times and the Lancet.

I am also indebted to Dr. Burton Chance, of Philadelphia, who arranged with the Assistant Editor of the American Medical Association Press to lend the block which illustrated his paper on the history of the ophthalmoscope in the Archives of Ophthalmology, March, 1935. This shows Carter at I suppose the age of fifty years. The other illustration is reproduced from the Vanity Fair cartoon, published April 9, 1892.

\section{REFERENCES}

1. WILKS and BETTANY.-Lives of eminent medical men.

2. Plarr's Lives of the Fellows of the Royal College of Surgeons of England.

\section{ANNOTATION}

\section{First Aid Treatment for Eye Injuries}

Recently there has been some discussion about the training and the limitations of First Aid workers. It seems that much of the instruction is given by laymen who have learnt their manuals with conscientious care and impart such information faithfully to their classes. The books on First Aid are mainly. limited to descriptions of the initial treatment of minor maladies and injuries. There is little or no provision for preparing first aid workers to deal with the severe multiple injuries inflicted by modern aerial bombardment. Also some of the advice in these books is out of date and has been reproduced in its archaic form through successive editions. The position in which a patient is placed on a stretcher according to the nature of his injury is often of vital importance and does not receive the attention it deserves.

The removal of foreign bodies from the eye has long been considered a justifiable hunting ground by the first aid enthusiast. This is indeed proper in the case of foreign bodies loose in the conjunctival sac when such can be removed skilfully and with a reasonable measure of surgical cleanliness. There are, however, first aid operators whose desire for further therapeutic adventures leads them to extend their attentions to foreign bodies impacted in 